\title{
Growth-climate relationships along an elevation gradient on a southeast-facing mountain slope in the semi-arid eastern Qaidam Basin, northeastern Tibetan Plateau
}

\author{
Zhi-Yong Yin ${ }^{1,3} \cdot$ Mingqi $\mathrm{Li}^{1} \cdot$ Yong Zhang $^{1} \cdot$ Xuemei Shao ${ }^{1,2}$
}

Received: 28 July 2015/Revised: 19 December 2015/ Accepted: 23 December 2015/Published online: 20 January 2016

(C) Springer-Verlag Berlin Heidelberg 2016

\begin{abstract}
Key message Both temperature and precipitation are strong factors of radial tree growth at all elevations in the semi-arid study area, except at the upper treeline where temperature becomes the major controlling factor.

Abstract Several recent studies across the Tibetan Plateau found consistent growth-climate relations at all elevations from the lower treelines to the upper treelines. These findings seem to challenge the general principle of dendroclimatology that precipitation serves as the controlling factor of radial tree growth at lower elevations while temperature serves as the controlling factor at higher elevations in semi-arid regions. Such conclusions also question the potential of temperature reconstruction using ringwidth data in these regions if precipitation remains the dominant factor of tree growth at the upper treelines. In this study, radial growth of Qilian juniper (Sabina przewalskii
\end{abstract}

Communicated by G. Wieser.

Electronic supplementary material The online version of this article (doi:10.1007/s00468-015-1348-3) contains supplementary material, which is available to authorized users.

Xuemei Shao

shaoxm@igsnrr.ac.cn

1 Key Laboratory of Land Surface Pattern and Simulation, Institute of Geographic Sciences and Natural Resources Research, Chinese Academy of Sciences, Beijing 100101, China

2 Chinese Academy of Sciences Center for Excellence in Tibetan Plateau Earth System Sciences, Chinese Academy of Sciences, Beijing 100101, China

3 Department of Environmental and Ocean Sciences, University of San Diego, San Diego, CA 92110, USA
Kom.) was examined along an elevation gradient between $\sim 3820$ and $4230 \mathrm{~m}$ in the mountains east of the Qaidam Basin, northeastern Tibetan Plateau, to determine the limiting factors of radial tree growth at different elevations. Rotated principal component analysis revealed two modes of variation patterns. The first mode presents mostly tree ring data from the lower elevation zones (3820-4100 m) and contains strong signals of precipitation variation. The second mode represents the higher elevation zones (approx. $4100-4230 \mathrm{~m}$ ) and contains strong signals of both temperature and precipitation variations. When signals of precipitation variation are removed from the tree ring data using partial correlation, the growth-temperature relationships become more evident on the upper slope. When correlations between individual tree-ring series and climate variables were examined, we discovered that there were better chances of finding tree ring samples strongly correlated to temperature variables $(r=0.6$ or higher) at the elevation zone within $\sim 100 \mathrm{~m}$ of the upper treeline, but uncommon at lower elevations. We also found that topographic variables, such as slope gradient and growingseason direct solar radiation may have minor influences on the growth-climate relationships.

Keywords Tree-ring width - Radial growth to climate relationships · Upper treeline $\cdot$ Temperature $\cdot$ Northeastern Tibetan Plateau

\section{Introduction}

Tree ring data have been extensively used in large-scale reconstructions of climate in the past 2000 years (e.g., Briffa et al. 2004; Cook et al. 2007, 2010; Mann et al. 2008; Neukom and Gergis 2012), which are based on the 
sensitivity of tree growth to climatic factors. It is well known that trees growing in harsh environments, especially those close to the limits of the growth ranges, have enhanced sensitivities to even minor climatic fluctuations and hence are optimal for climate reconstruction (Fritts 1976). Since multiple climatic factors may act as the controls of tree growth, a common sampling strategy in dendroclimatology is to carefully select the sampling site so that only one climatic factor would serve as the sole or dominant limiting factor of tree growth (Fritts 1976; Sheppard 2010). Therefore, trees near the high latitudinal or the upper elevational forest limits are often used for temperature reconstructions, while those from arid forest limits are used for reconstructions of moisture conditions (Fritts 1976). These general principles have been practiced and validated in numerous successful reconstructions of past climate worldwide, which were consequently used in large-scale and regional climatic reconstructions (e.g., Briffa et al. 2004; Cook et al. 2007, 2010).

Sometimes, however, there have been also challenges in practicing these principles of dendroclimatology, especially in mid-latitude semi-arid highland regions and where researchers have limited choices of sampling sites with old growth stands. As the result, radial tree growth at study sites may be controlled by multiple factors, rather than a single dominant factor. For example, Graumlich (1991, 1993) determined that the growth of subalpine coniferous trees in the Sierra Nevada was influenced by both previous winter-spring precipitation and summer temperature. On the other hand, the presumed control factor, specifically temperature at the upper treelines, may not manifest its signals clearly in the tree-ring records. Esper et al. (2007) combined samples from 28 juniper ring-width chronologies into two composites of high- and low-elevations in the Tien Shan and Karakorum region, based on the distances to the upper treeline. They found that both series contained strong common signals and concluded that in this large region, there was strong homogeneity in growth trends in response to similar climatic signals, and that trees growing at the upper treeline sites and those at sites below the upper treeline did not differ substantially in their growth-climate relationships. A recent study by $\mathrm{He}$ et al. (2013) sampled two sites of Juniperus tibetica on the southern Tibetan Plateau, at four elevations along altitude gradients ranging from 4005 to $4485 \mathrm{~m}$ above sea level (a.s.1.). They concluded that elevation has no significant effects on tree growth. Similarly, Yang et al. (2013) sampled Qilian junipers (Sabina przewalskii Kom.) at four sites on a mountain slope, from the lower- to upper-treeline in the semi-arid Qilian Mountains area, and found that precipitation remained the major limiting factor of tree growth for all sites within the elevation range from 3000 to $3520 \mathrm{~m}$ a.s.l. They attributed their findings to the generally dry climatic conditions of the region. Another recent study examined samples of Qilian junipers also in the Qilan Mountains of the northeastern Tibetan Plateau (Gao et al. 2013). Instead of sampling sites with broad elevation ranges as in He et al. (2013) and Yang et al. (2013), they sampled in four narrow elevation zones of $20-40 \mathrm{~m}$ on a single slope ranging from 3200 to $3600 \mathrm{~m}$. Their results did not show general trends of decreased sensitivity of tree growth to precipitation and increased sensitivity to temperature as elevation increases.

Associated with different responses of tree growth to climatic factors at different altitudes, there is also a large body of literature on the responses of tree growth to climate at the upper treeline sites as summarized in a volume by Körner (2012). Applying the general principles of dendroclimatology as mentioned above, it can be assumed that at the upper treeline thermal condition or temperature is the limiting factor of tree growth, which should be reflected in the growth-climate relationship. However, several studies have indicated strong moisture signals in tree-ring records from upper treeline sites in the northeastern Tibetan Plateau. For example, Liu et al. (2006) compared the growthclimate relationships of Qilian junipers between the upper and lower treelines in Dulan of Qinghai Province, and found that the chronologies from both upper and lower treelines had similar responses to moisture conditions. However, they did not observe persistently enhanced relationships to temperature at the upper treeline sites. This pattern was confirmed by a recent study by Qin et al. (2013) in Delingha, approximately $130 \mathrm{~km}$ to the northwest of Dulan, who found that growth of Qilian junipers sampled at the upper treeline $(4020 \mathrm{~m})$ was still mainly controlled by precipitation. Peng et al. (2008) also found that precipitation was an important limiting factor for upper treeline sites located on the drier west-facing slopes in the A'nyêmaqên Mountains. Only trees growing at the wetter treeline sites were more sensitive to temperature variations.

Judging from the above discussion, it can be seen that the growth-climate relationships at different elevations or at the upper and lower treelines may have complex patterns that depend on the overall regional climatic conditions as well as topographic controls. This means that sampling sites simply qualified as the upper treelines may not always have temperature as the single major controlling factor for tree growth. Additionally, at the time of sampling in the field, it might be difficult to determine whether the observed upper tree limit is a true climatic treeline (Körner 1998; Berdanier 2010), or a topographic treeline. Because of the growing needs for climate reconstructions with increasing spatial and temporal coverage, it is important to understand the patterns of variation in the growth-climate relationships in different microenvironments. Such knowledge may provide guidance to searching for proper 
sampling sites with a specific limiting climatic factor and offer insight into post-sampling data processing and screening strategies for climate reconstruction purposes.

The mountains in the eastern Qaidam Basin have rendered millennium-long records of tree ring data, but most previous study sites have been found to be moisture sensitive (e.g., Zhang et al. 2003; Sheppard et al. 2004; Yin et al. 2008; Shao et al. 2010), because of the regional semi-arid climatic conditions. So far there is only one temperature reconstruction explicitly based on Qilian juniper ring-width samples from the upper treeline in this region (Zhu et al. 2008). Since trees growing along the upper treelines tend to be relatively young due to the treeline dynamics, a common practice is to find old trees in the zones 50-100 m below the upper treeline for the purpose of climate reconstruction. So the question is whether trees growing at this zone are still sensitive to temperature variations to the extent that their ring width variations contain sufficient temperature signals for reconstruction. The purpose of this study is to examine the variation patterns of the relationships of radial tree growth to climate variables along an elevation gradient with relatively fine $(\sim 30-40 \mathrm{~m})$ vertical increments at a site near Dulan of the eastern Qaidam Basin. We also intend to explore the effects of climatic and topographic factors that could best explain such variation patterns. Following the general principles of dendroclimatology, we hypothesize that in the semi-arid mountainous study region, precipitation is the major limiting factor of radial tree growth at lower elevations and temperature is the major limiting factor at the upper treeline. Additionally, we hypothesize that topographic factors that influence distributions of moisture and solar radiation on the sloped terrain may affect the radial tree growth to climate relationships.

\section{Materials and methods}

\section{Study region and sampling site}

The study region is located in the mountains along the eastern margin of the Qaidam Basin, northeastern Tibetan Plateau (Fig. 1). All climatic data used in this study were obtained from the Climate Data Center of China Meteorological Administration (CMA) (http://cdc.cma.gov.cn/). The analysis of growth-climate relations was performed using instrumental data from the weather station of Dulan. The study region has a semi-arid continental climate, with cold and dry winters and warm and moist summers (Fig. 2). Annual total precipitation is $218 \mathrm{~mm}$ during 1981-2010 with the majority $(177 \mathrm{~mm})$ occurring during MaySeptember. Mean annual temperature is $3.5{ }^{\circ} \mathrm{C}$ with January as the coldest month $\left(-9.4{ }^{\circ} \mathrm{C}\right)$ and July as the warmest month $\left(15.2{ }^{\circ} \mathrm{C}\right)$. The elevation of the weather station is $3192.1 \mathrm{~m}$ a.s.l. at the foothills, while the mountain peaks can often reach $4500 \mathrm{~m}$ or higher.

Our study site is in Errige $\left(36.18^{\circ} \mathrm{N}, 98.55^{\circ} \mathrm{E}\right)$, approximately $43 \mathrm{~km}$ southeast of the town of Dulan, which is referred to as ERG in the following (Fig. 1). At this site, we selected a predominantly SE-facing slope where the Qilian juniper ( $S$. przewalskii Kom.) forest is distributed from approximately $3820-4230 \mathrm{~m}$ a.s.1., with relatively welldefined lower and upper treelines (Fig. 3). The local peak reaches approximately $4845 \mathrm{~m}$ and the upper tree limit we sampled is the highest in the surrounding area. Elevation of the valley bottom near the lowest sampling elevation is approximately $3810 \mathrm{~m}$ and the lowest tree limit is located at least $10 \mathrm{~m}$ above the valley bottom (Fig. 3). Inside this valley, there are no permanent structures of human settlements, although herds of sheep, goats, and yaks are visible at times. The forest stands seemed to be undisturbed without any signs of extensive logging activities. Soils at the sampling site are mostly thin and rocky on steep slopes, while thick soils are found in hollows and on gentle slopes. At the lower portion of the sampling slope, soils are compacted due to heavy animal traffic. We sampled a minimum of 20 trees (with diameters greater than $20 \mathrm{~cm}$ at the breast height) for each elevation cluster with $\sim 30-\mathrm{m}$ increments for a total of 14 clusters (E01-E14, Fig. 3). Two cores were extracted from each tree at the breast height ( $\sim 1.3 \mathrm{~m}$ from the ground) using increment borers. Whenever possible, the two cores were located on opposite sides of the tree at the direction parallel to the contour (Fritts 1976). For all the trees sampled, we took the geographic locations and elevations using hand-held GPS units. Occasionally, when two trees were located within $5 \mathrm{~m}$ to each other, both were given the same latitude and longitude. A total of 358 trees were recorded in the field, with 680 cores.

\section{Elevations of individual trees}

Since the vertical accuracies of consumer-grade hand-held GPS units tend to be much lower than the horizontal accuracies of approximately 3-10 m (http://water.usgs. gov/osw/gps/; Wing et al. 2005), we decide to use the GPS horizontal locations to extract elevation data from the digital elevation models (DEM) based on the ASTER images (Lang and Welch 1999) (see Supplementary Materials (SM) 1 for details). This also allows us to perform terrain analyses using the DEM data to characterize the growth environments of individual trees sampled. We extracted slope gradient and April to August direct solar radiation based on the ASTER DEM for individual trees (SM 1). Slope gradient may influence the sensitivity of radial tree growth to precipitation through its influence on soil properties and residence time of runoff for infiltration. 


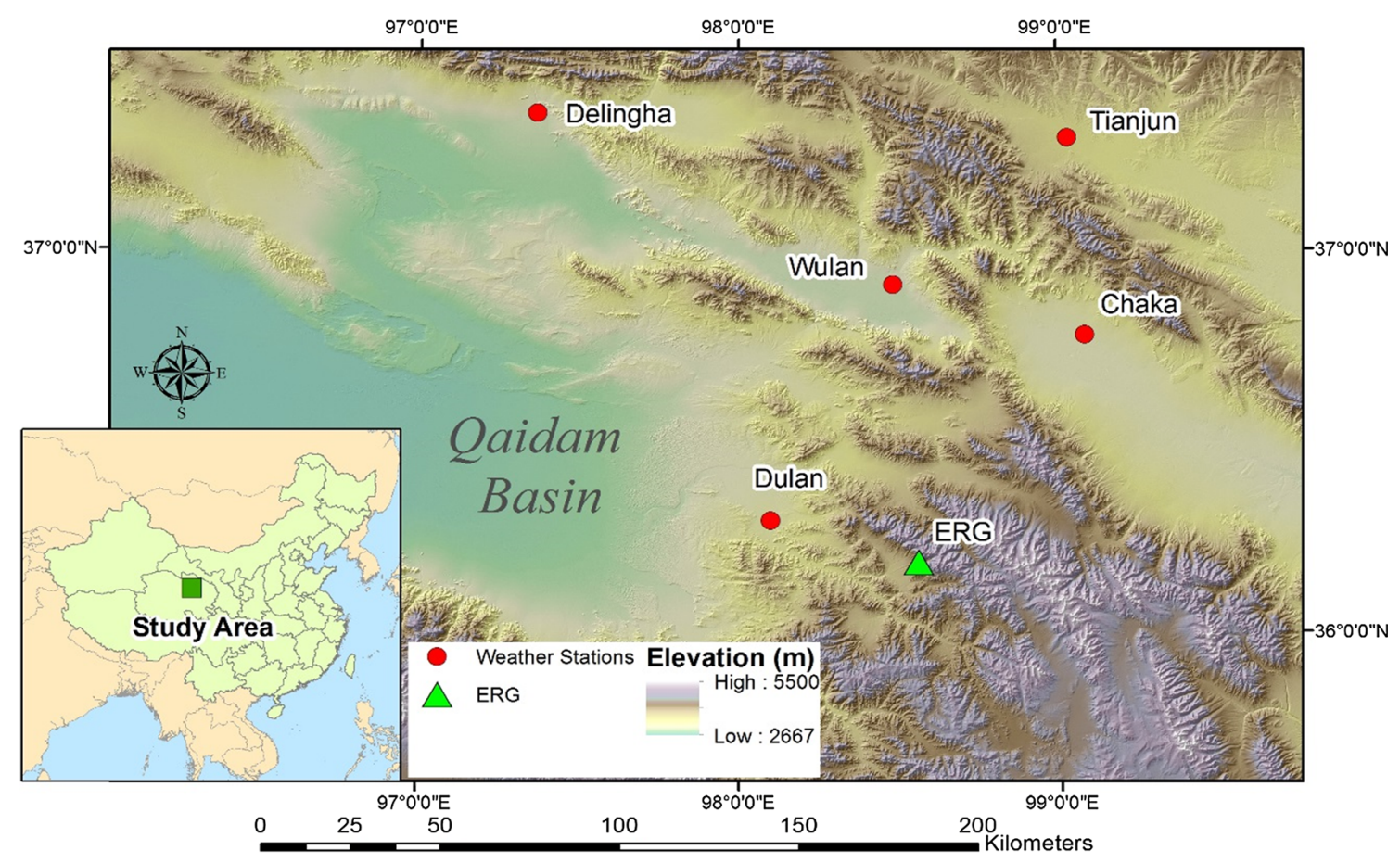

Fig. 1 Study region: weather stations, sampling site Errige (ERG), and topography near Dulan County of Qinghai Province, northeastern Tibetan Plateau

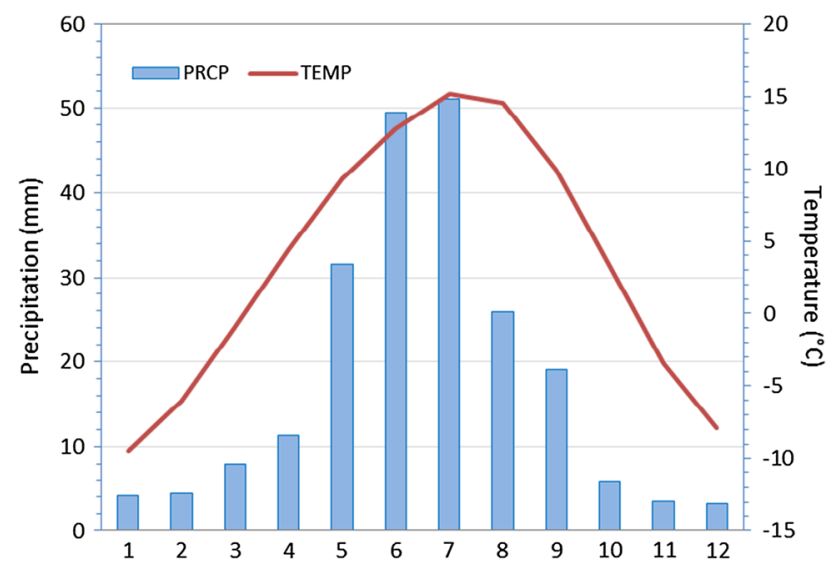

Fig. 2 Long-term (1981-2010) mean temperature (TEMP) and precipitation (PRCP) by months for Dulan, Qinghai Province

For sites with higher levels of direct solar radiation, tree growth may be less sensitive to temperature variations. Additionally, higher solar radiation may lead to higher demands for moisture due to enhanced evapotranspiration rates and hence increase the sensitivity of radial tree growth to moisture conditions.

\section{Ring-width chronology development}

The cores were first dried naturally in the lab, and then we followed the standard processing steps as described in
Stokes and Smiley (1968) to mount and sand the cores. All cores sampled were cross-dated according to the ring-width variation patterns and the ring widths were measured using a LINTAB Tree Ring Measurement System to the $0.01 \mathrm{~mm}$ accuracy. The COFECHA program was used to check the quality of dating and measuring (Holmes 1983).

Due to overlapping elevations between the 14 sampling clusters (E01-E14) as seen in Fig. 3, we reclassified the trees into ten distinct elevation zones according to the ASTER DEM elevation values (Table 1a) and constructed chronologies for each of the elevation zones, named as ERG1-ERG10 hereafter. A total of 558 cores from 303 trees were used in chronology construction, excluding cores shorter than 100 years of lengths. The cores were detrended using either a negative exponential function or a negative linear function to remove growth trends for the entire sample lengths (Fritts 1976; Cook and Kairiukstis 1990). This method is appropriate for open-canopy forests in semi-arid regions where competition by adjacent trees is not a major factor of radial growth rate. The standard chronologies are used in the following analyses. Since the focus of this study is the analysis of growth-climate relationship and climatic data are only available since 1954, we present the ring-width chronologies during $1801-2010$ as the context. For this period, there are 313 complete series from 192 trees.

Table 1 summarizes the general characteristics of the ten chronologies for the full chronologies (Table 1b) and 
Fig. 3 Clusters of trees sampled overlaid on Google Earth image at the sampling site in Errige (ERG). A total of 14 elevation clusters were sampled in the field as E01-14, but later regrouped according elevations of individual trees into ten groups as ERG1-10 (see text for details)

Table 1 Ranges and means of the ten elevation zones ERG1ERG10 (a), summary of statistics for the full-length chronologies (b), and those of the common period 1801-2010 (c)

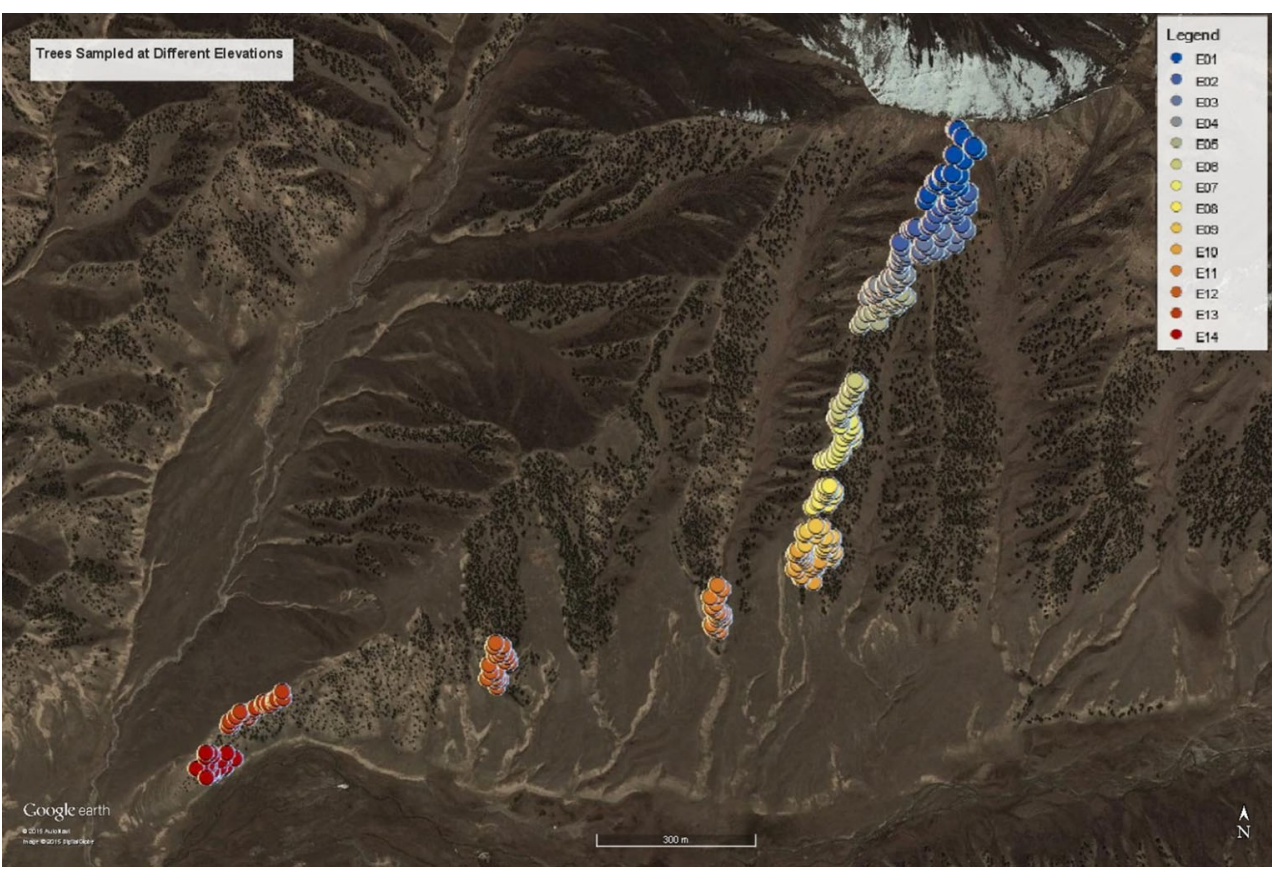

\begin{tabular}{|c|c|c|c|}
\hline & Minimum & Maximum & Mean \\
\hline \multicolumn{4}{|l|}{ (a) DEM elevations (m) } \\
\hline ERG1 & 4201.8 & 4231.4 & 4214.9 \\
\hline ERG2 & 4176.4 & 4198.8 & 4190.0 \\
\hline ERG3 & 4143.5 & 4165.2 & 4152.9 \\
\hline ERG4 & 4100.0 & 4137.7 & 4117.8 \\
\hline ERG5 & 4026.9 & 4071.0 & 4053.1 \\
\hline ERG6 & 3982.0 & 4020.2 & 4006.1 \\
\hline ERG7 & 3942.0 & 3976.9 & 3958.8 \\
\hline ERG8 & 3901.0 & 3931.0 & 3916.5 \\
\hline ERG9 & 3869.0 & 3892.7 & 3883.7 \\
\hline ERG10 & 3827.0 & 3855.9 & 3841.2 \\
\hline \multicolumn{4}{|l|}{ (b) Full-chronology statistics } \\
\hline First year & -725 & 1143 & 137.3 \\
\hline Total length & 868 & 2736 & 1873.7 \\
\hline$\%$ Missing rings & 0.187 & 1.045 & 0.5475 \\
\hline Mean segment length & 292.9 & 526.1 & 449.0 \\
\hline \multicolumn{4}{|l|}{ (c) 1801-2010 common period } \\
\hline Number of trees/cores & $11 / 19$ & $36 / 65$ & $19 / 31$ \\
\hline Variance explained by PC1 & $39.9 \%$ & $51.6 \%$ & $46.4 \%$ \\
\hline All-series rbar & 0.364 & 0.489 & 0.431 \\
\hline Within-tree rbar & 0.734 & 0.911 & 0.817 \\
\hline Between-tree rbar & 0.341 & 0.480 & 0.420 \\
\hline Signal-to-noise ratio (SNR) & 10.9 & 39.6 & 23.6 \\
\hline Expressed population signal (EPS) & 0.916 & 0.975 & 0.955 \\
\hline Mean width index & 1.02 & 1.18 & 1.07 \\
\hline Standard deviation & 0.38 & 0.57 & 0.45 \\
\hline Mean sensitivity & 0.27 & 0.42 & 0.35 \\
\hline First-order autocorrelation & 0.48 & 0.63 & 0.55 \\
\hline
\end{tabular}


chronology statistics for the common period 1801-2010 (Table 1c). Comparing our chronologies with other Qilian juniper chronologies in this region (e.g., Zhang et al. 2003; Sheppard et al. 2004; Yin et al. 2008; Zhu et al. 2008; Liu et al. 2009; Gao et al. 2013; Qin et al. 2013; Yang et al. 2013), both the mean sensitivity and signal-to-noise ratio (SNR) values are in the mid- to upper-range of the reported values, while the between-tree rbar and all-series rbar values are somewhat lower than those reported in other studies (Table 1c). Also lower are the percentages of variance explained by $\mathrm{PC} 1$, probably as a result of our sampling strategy of coring trees of all ages (Table 1c). The expressed population signal (EPS) values at all elevations are fairly consistent, ranging from 0.916 to 0.975 (Table 1c). Variations in the chronology statistics in different elevation zones and their explanations are presented in SM2.

When the ring-width chronologies are plotted over time during the common period, it can be seen that enhanced growth occurred since the 1900s, especially near the upper treeline (Fig. 4a). Additionally, the ten chronologies show strong temporal consistency during this period (Fig. 4b), suggesting similar responses to common climatic factors at this site.

\section{Growth-climate relationship analysis}

Due to possible data quality problems in the earlier instrumental period of 1954-2010, especially for temperature data (see SM 3 for details), we decided to use the climatic data during 1970-2010 for the radial growth-climate analysis. The growth-climate relationships were first investigated using Pearson's correlation for the period 1970-2010, in which time-series of temperature and precipitation of different months and seasons were correlated with the ring-width chronologies of different elevation zones. In this analysis, we considered both original data and the first-difference series of tree ring series and climatic variables, which represented variation patterns in the high-frequency domain. Since both temperature and precipitation might act as the factors of radial tree growth, we also used partial correlation to remove the effects of one climatic factor and examined whether the other climatic factor still had statistically significant relations with radial tree growth. For example, when tree ring series were correlated with various temperature variables, a precipitation variable served as the control variable, and vice versa.

Based on the findings by Liu et al. (2006) and Qin et al. (2013), it is expected that the tree-ring series sampled at different elevations have strong covariation patterns at this site. To discern the distribution of variances among the interrelated series, rotated principal component analysis (RPCA) was used to identify orthogonal modes of variation patterns representing tree growth patterns unique at different elevations, in a way similar to applications of RPCA in climate regionalization (Richman 1986; White et al. 1991). The scores of the rotated principal components (RPCs) were then used in correlation analysis with the climatic factors. In this way, we hope to differentiate elevation zones in which either temperature or precipitation serves as the major controlling factor of radial tree growth.

Growth-climate relationships obtained from individual trees may reveal important information for ecological processes. This may also reveal patterns that might have been obscured by grouping trees growing in different microenvironments within the same elevation zone. We calculated Pearson's correlations between individual treering series and climatic variables. Then the growth-climate correlation coefficients were treated as variables in a correlation analysis with topographic variables to investigate how such relationships may be influenced by elevation, slope gradient, and solar radiation. For this analysis, we used 217 trees with more than 25 years of data during 1970-2010, while the topographic variables were retrieved from the ASTER DEM data as described above.

\section{Results and discussion}

\section{Growth-climate relationships}

Figure 5 shows that tree ring series at all elevations (ERG1-ERG10) follow similar trends in correlations with maximum $\left(T_{\max }\right)$, minimum $\left(T_{\min }\right)$ and mean $\left(T_{\text {mean }}\right)$ temperatures and precipitation (PRCP) from previous May to current September. The ring-width chronologies are generally positively correlated to the mid-summer and coldmonth temperatures, but negatively correlated to temperatures in late-spring to early-summer (Fig. 5a, c, e). In most months the correlations to temperatures are not statistically significant. There are greater differences among the elevation zones in the correlations to $\mathrm{T}_{\max }$ from January to June than those to $T_{\min }$, but this pattern is reversed for the months of July-September (Fig. 5a, c). Of the individual elevation zones, ERG1, ERG5, and ERG6 seem to stand out from the rest. For the correlations of the first-difference data, however, the variation patterns become more consistent among the elevation zones and only ERG1 remains to be separated from the rest (Fig. 5b, d, h). Generally, the correlations of the first-difference data follow the same patterns of the original data, except for the months of previous December and current September temperatures when the signs of correlations to temperature variables are almost reversed (Fig. 5b, d, f). Due to the similarities among the temperature variables, we will focus on $T_{\text {mean }}$ in the following analysis. 

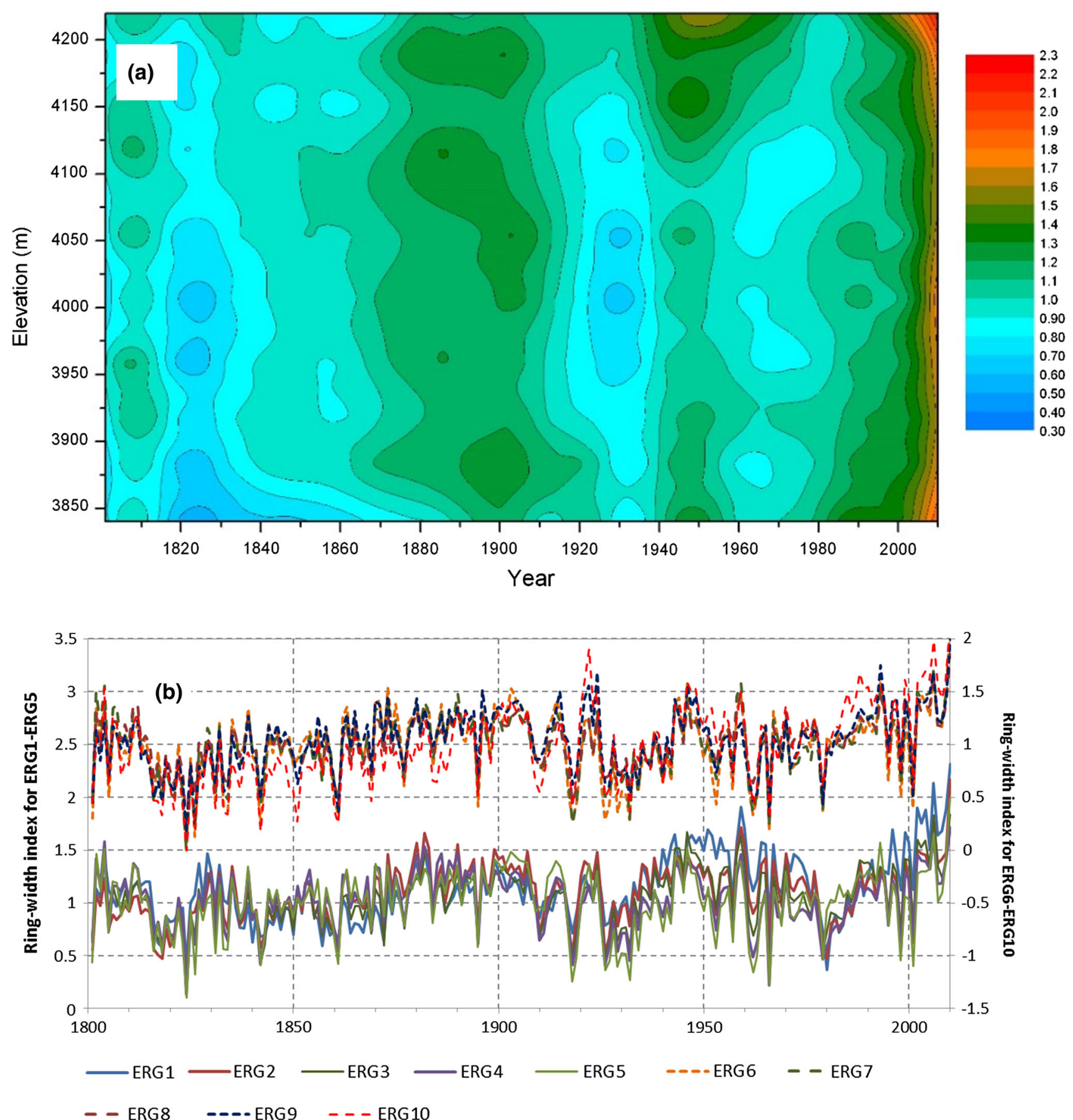

Fig. 4 Annual radial growth at different elevations represented by ring-width indices during 1801-2010 (a), and ring-width index timeseries of the ten chronologies plotted during 1801-2010 (b). The ten

chronologies are divided into two groups (ERG1-5 and ERG6-10) for the ease of viewing

There are positive correlations of tree ring data with precipitation in both the current and previous growing seasons (previous May-August and current May-July), especially for the elevations below $4100 \mathrm{~m}$ (ERG4 and lower) (Fig. 5g). Comparing with the results for the temperature variables, the relationships between precipitation and tree growth are more persistent at all elevations in the

sense that both the original and first-difference data produced correlations of similar strengths (Fig. $5 \mathrm{~g}, \mathrm{~h}$ ). Only at the highest elevation zones (ERG1 and ERG2), this relationship breaks down, where relatively high correlations in the original precipitation are not matched by the first-difference data, especially for the month of May (Fig. $5 \mathrm{~g}, \mathrm{~h}$ ). For correlations to both temperature and precipitation 
(a) Tmax

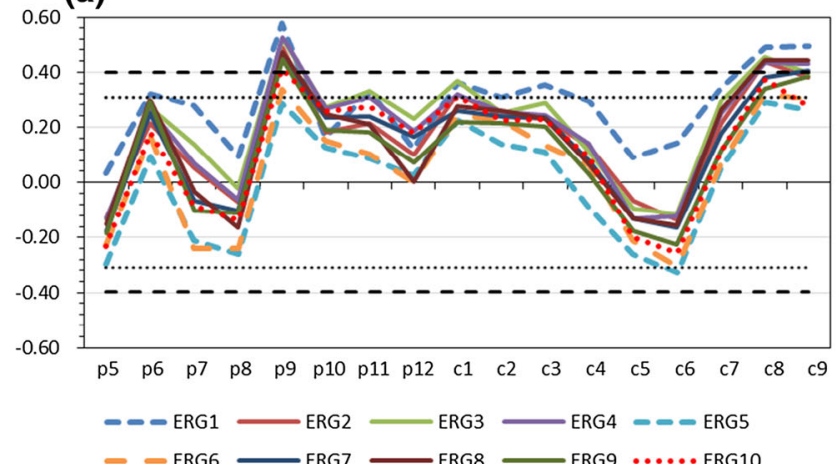

(c)

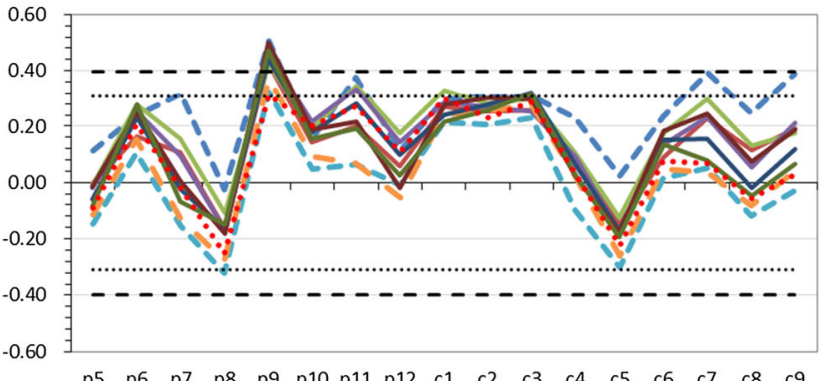

- ERG1 ERG2 ERG3 - ERG4 - - ERG5

- ERG6 ERG7 - ERG8 -ERG9 .....ERG10

(e) Tmean

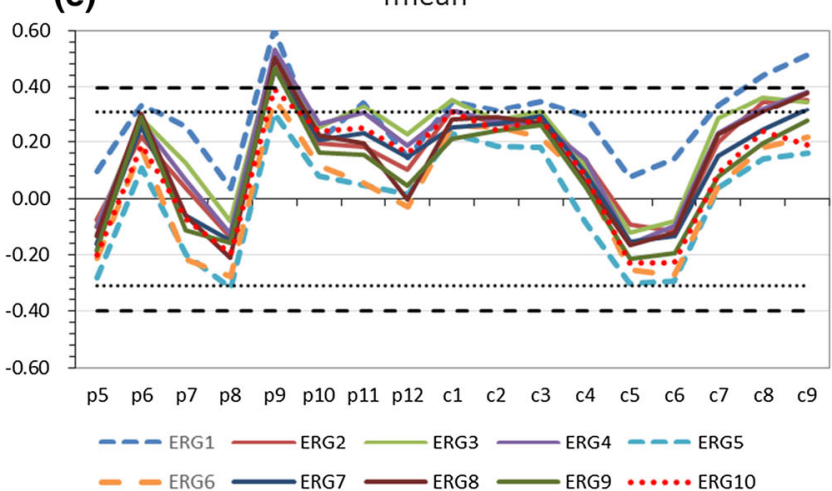

(g)

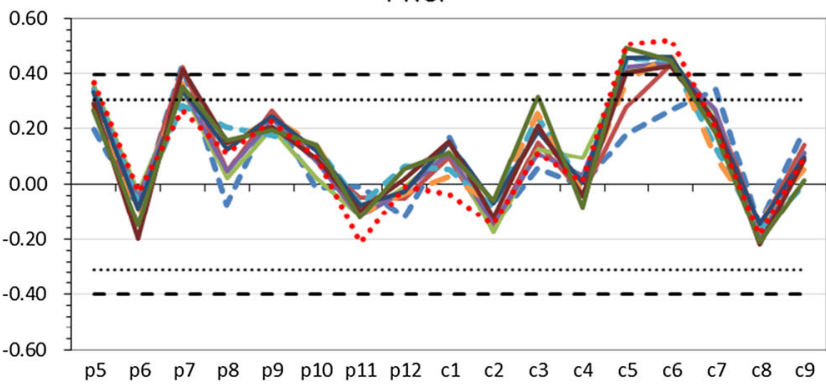

- - ERG1 ERG2 ERG3 - ERG4 - - ERG5

- - ERG6 ERG7 —ERG8 —ERG9 ...... ERG10 (b)

Tmax 1st DIFF

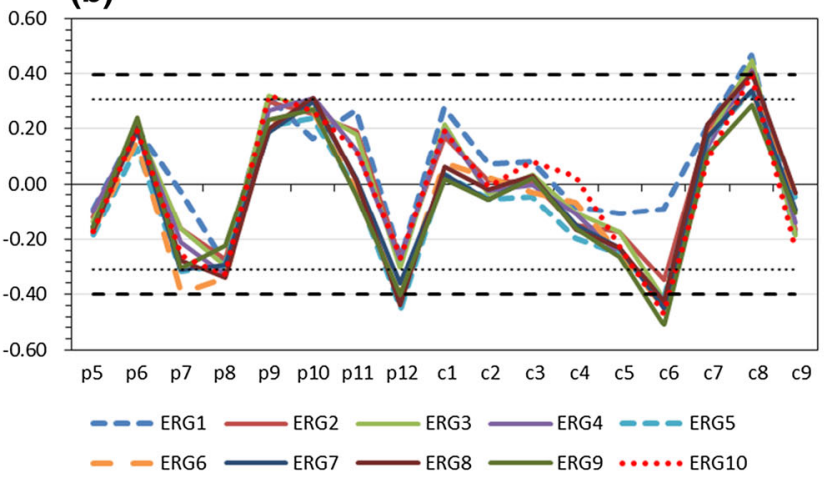

(d)

Tmin 1st DIFF

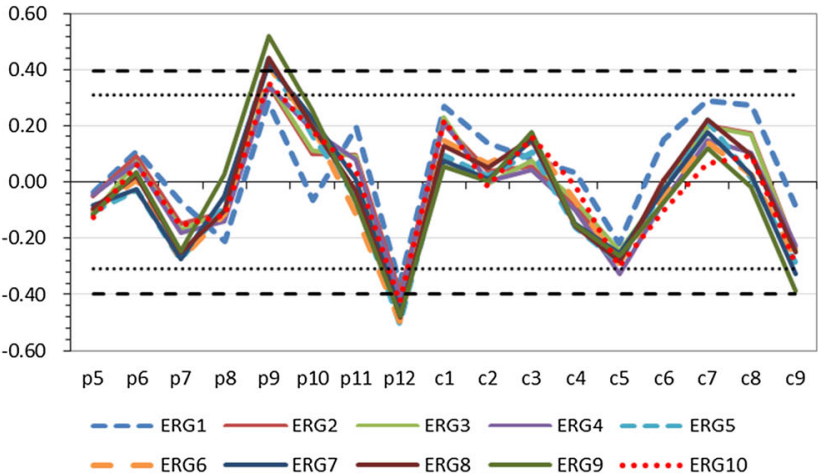

(f)

Tmean 1st DIFF

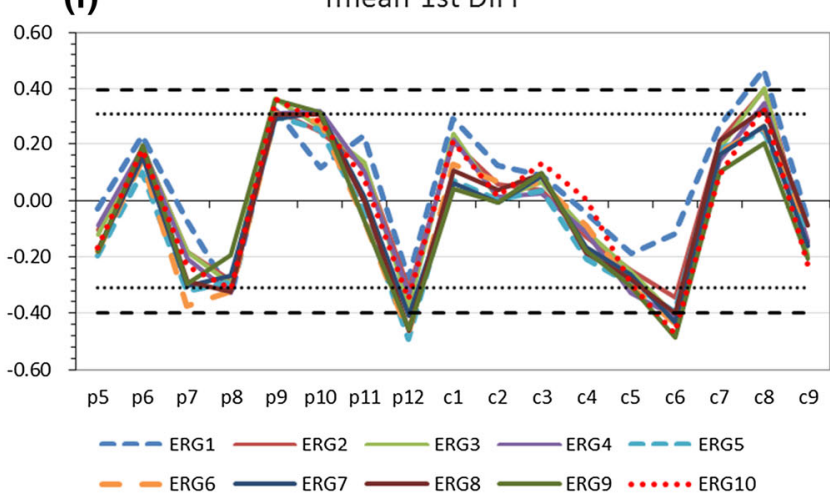

(h)

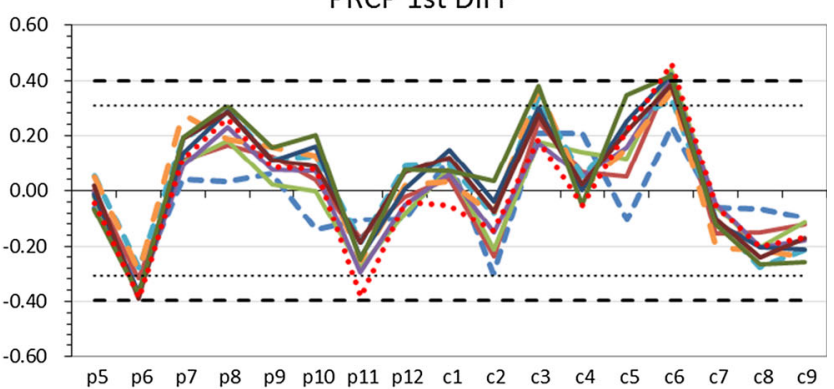

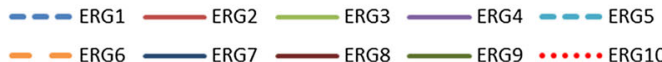


4Fig. 5 Correlation coefficients of tree ring chronologies at different elevations to a maximum temperature $\left(T_{\max }\right), \mathbf{c}$ minimum temperature $\left(T_{\text {min }}\right)$, e mean temperature $\left(T_{\text {mean }}\right)$, and $\mathbf{g}$ precipitation $(\mathrm{PRCP})$ from previous May (p5) to current September (c9), as well as correlations of the first difference tree-ring series to the respective first-difference climate variables (1st DIFF in b, d, f, h) using data for 1970-2010. The horizontal dotted and dashed lines represent the 0.05 and 0.01 significance levels, respectively

variables, the highest elevation zone (ERG1) appears to stand out, consistently with higher correlations to temperature variables and lower correlations to precipitation than the other elevation zones.

Table 2 summarizes the results of growth-climate analysis with a focus on various seasonal combinations of the climatic variables. For temperature variables, we include summer (current July-August) and winter (previous September-current March) seasons, while for precipitation we consider early growing season (May-July) and annual (previous July-current June) totals. The correlations between radial growth and May-June precipitation (not presented) are comparable to those with May-July precipitation. In general, precipitation variables have stronger correlations with radial tree growth than the temperature variables at all elevations, except for ERG1. It can be seen that stronger correlations with the temperature variables are found mostly at higher elevations, while stronger correlations with precipitation variables are generally found at lower elevations (Table 2). There is a tendency of statistically significant correlations with temperatures becoming more sporadic toward the lower elevations, while the relationships with precipitation maintain fairly persistent.
Based on the above results, we select the most persistent temperature and precipitation variables as the control variables in partial correlation analysis. For the relationships between the ring-width chronologies and precipitation variables (current May-July as Pc567 and previous July-current June as Pp7c6), winter temperature (previous September-current March as Tp9c3) is used as the control variable. Inversely, for the correlations between the treering series and temperature variables (current July-August as Tc78 and Tp9c3), annual precipitation (Pp7c6) is used as the control variable. Figure 6 a shows again that growthprecipitation relationships maintain persistently strong at all elevations except for the highest elevation zone, with the effects of temperature being removed by the control variable Tp9c3. On the other hand, growth-temperature relationships are stronger at the higher elevation zones (Fig. 6b), especially for summer temperature (Tc78). Weaker, but still statistically significant relationships with winter temperature $(\mathrm{Tp} 9 \mathrm{c} 3)$ can be found at lower elevations, while the middle section (ERG5-6) is where the growth-temperature correlations are weakest. Winter temperature has more robust signals in the tree ring data than summer temperature in all elevation zones (Fig. 6b).

Because of the semi-arid setting of our study region, the influence of precipitation on radial growth of trees in this region has been well documented in previous studies (e.g., Zhang et al. 2003; Sheppard et al. 2004; Shao et al. 2005, 2010; Yin et al. 2008). Positive correlation between radial tree growth and summer temperature (Tc78) reflects the limiting effects of low temperature on biological processes due to high elevation. The effects of winter temperature (Tp9c3) on radial growth of trees in the following growing

Table 2 Pearson's correlation coefficients between ring-width chronologies and seasonal/annual climatic variables at different elevation zones for 1970-2010 $(N=41)$

\begin{tabular}{|c|c|c|c|c|c|c|c|c|}
\hline \multirow{2}{*}{$\begin{array}{l}\text { Elevation } \\
\text { zones }\end{array}$} & \multicolumn{2}{|l|}{$T_{\max }$} & \multicolumn{2}{|l|}{$T_{\min }$} & \multicolumn{2}{|l|}{$T_{\text {mean }}$} & \multicolumn{2}{|l|}{ PRCP } \\
\hline & $\begin{array}{l}\text { Current } \\
\text { July- } \\
\text { August }\end{array}$ & $\begin{array}{l}\text { Previous } \\
\text { September- } \\
\text { current March }\end{array}$ & $\begin{array}{l}\text { Current } \\
\text { July- } \\
\text { August }\end{array}$ & $\begin{array}{l}\text { Previous } \\
\text { September- } \\
\text { current March }\end{array}$ & $\begin{array}{l}\text { Current } \\
\text { July- } \\
\text { August }\end{array}$ & $\begin{array}{l}\text { Previous } \\
\text { September- } \\
\text { current March }\end{array}$ & $\begin{array}{l}\text { Current } \\
\text { May- } \\
\text { July }\end{array}$ & $\begin{array}{l}\text { Previous } \\
\text { July-current } \\
\text { June }\end{array}$ \\
\hline ERG1 & $0.51 * * *$ & $0.59 * * *$ & $0.41 * *$ & $0.53 * * *$ & $0.48 * *$ & $0.60 * * *$ & $0.45^{* *}$ & $0.45^{* *}$ \\
\hline ERG2 & $0.38 *$ & $0.46^{* *}$ & 0.22 & $0.41 * *$ & $0.33 *$ & $0.47 * *$ & $0.54 * * *$ & $0.61 * * *$ \\
\hline ERG3 & $0.45^{* *}$ & $0.58 * * *$ & 0.28 & $0.53 * * *$ & $0.40 * *$ & $0.59 * * *$ & $0.61 * * *$ & $0.62 * * *$ \\
\hline ERG4 & $0.41 * *$ & $0.54 * * *$ & 0.19 & $0.50 * * *$ & $0.34 *$ & $0.55 * * *$ & $0.61 * * *$ & $0.63 * * *$ \\
\hline ERG5 & 0.19 & 0.26 & -0.04 & 0.28 & 0.10 & 0.28 & $0.55 * * *$ & $0.67 * * *$ \\
\hline ERG6 & 0.22 & $0.32 *$ & -0.03 & $0.33 *$ & 0.13 & $0.33 *$ & $0.50 * * *$ & $0.68 * * *$ \\
\hline ERG7 & $0.33 *$ & $0.47 * *$ & 0.09 & $0.47 * *$ & 0.24 & $0.48 * *$ & $0.61 * * *$ & $0.69 * * *$ \\
\hline ERG8 & $0.42 * *$ & $0.44 * *$ & 0.21 & $0.45 * *$ & $0.33^{*}$ & $0.46^{* *}$ & $0.57 * * *$ & $0.68 * * *$ \\
\hline ERG9 & 0.26 & $0.39 *$ & 0.02 & $0.41 * *$ & 0.16 & $0.40 * *$ & $0.60 * * *$ & $0.70 * * *$ \\
\hline ERG10 & 0.28 & $0.49 * *$ & 0.01 & $0.44 * *$ & 0.19 & $0.49 * *$ & $0.66 * * *$ & $0.66 * * *$ \\
\hline
\end{tabular}

* Significant at the 0.05 level; ** significant at the 0.01 level; *** significant at the 0.001 level 

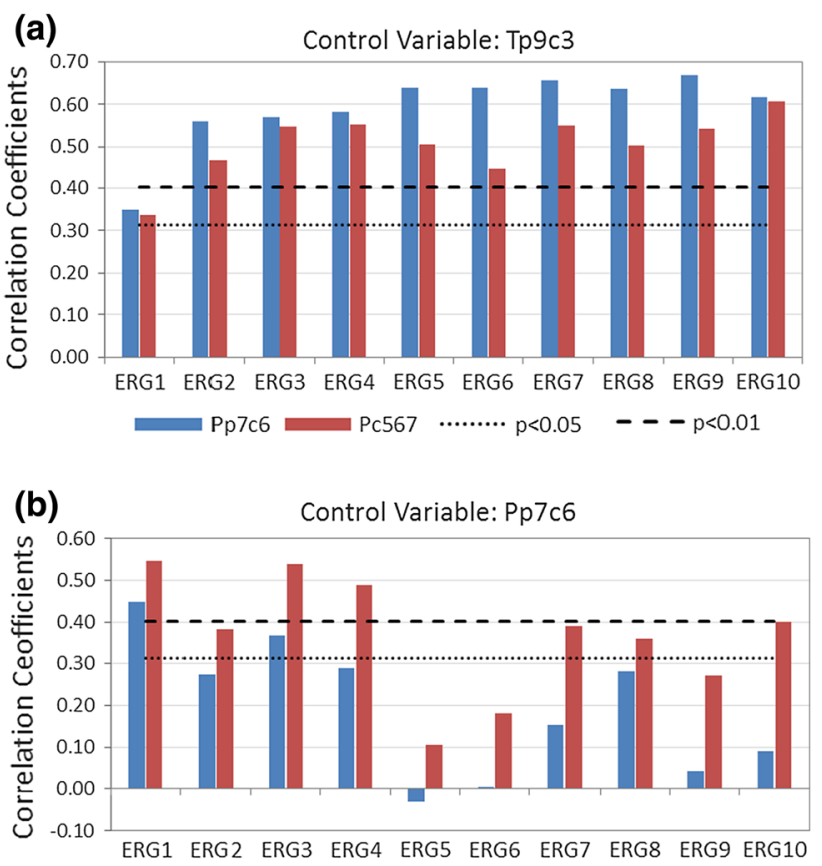

Fig. 6 Partial correlation coefficients $(d f=38)$ between tree ring chronologies and a precipitation variables-current May-July precipitation (Pc567) and annual precipitation (previous July-current June, Pp7c6), with winter temperature (previous September-current March, Tp9c3) as the control variable; and b temperature variables: July-August temperature (Tc78) and winter temperature $(\mathrm{Tp} 9 \mathrm{c} 3)$, with annual precipitation (Pp7c6) as the control variable for the ten elevation zones. The dotted and dashed lines represent significance levels

season, reflected as positive correlations, can be explained by several processes (Fritts 1976). Warmer winter temperatures can cause melting of snow cover and infiltration of melt water will create better soil moisture conditions at the beginning of the next growing season. Extremely cold winter temperatures may damage the trees and slow down the growth later, while warmer temperatures in the late winter may speed up the recovery of trees from dormancy, essentially extending the growing season. In addition, even in winter, there is limited photosynthesis for coniferous trees. With higher winter temperature, photosynthesis is able to compensate for the nutrient demand by respiration and reduce the depletion of the nutrient reserve, so that the growth in the following year is enhanced.

The best distinction between elevations where temperature or precipitation variables serve as the main controlling factors comes from results of rotated principal component analysis (RPCA) using data during 1970-2010 for the ten chronologies (ERG1-ERG10). The first unrotated principal component (PC1) explains more than $87 \%$ of the total variance, while the eigenvalue of $\mathrm{PC} 2$ is lower than 1.0 (0.739), showing strong covariation among these
Table 3 Unrotated and rotated PC loadings of the ten ring-width chronologies obtained from principal component analysis using data for the period 1970-2010

\begin{tabular}{lccccc}
\hline & \multicolumn{2}{c}{ Unrotated loadings } & & \multicolumn{2}{c}{ Rotated loadings } \\
\cline { 2 - 3 } & PC1 & PC2 & & RPC1 & RPC2 \\
\hline ERG1 & 0.800 & 0.581 & & 0.262 & 0.953 \\
ERG2 & 0.930 & 0.282 & & 0.551 & 0.801 \\
ERG3 & 0.956 & 0.181 & & 0.634 & 0.738 \\
ERG4 & 0.975 & 0.148 & & 0.670 & 0.724 \\
ERG5 & 0.923 & -0.322 & & 0.922 & 0.324 \\
ERG6 & 0.934 & -0.276 & & 0.902 & 0.368 \\
ERG7 & 0.971 & -0.131 & & 0.840 & 0.503 \\
ERG8 & 0.968 & -0.010 & & 0.762 & 0.597 \\
ERG9 & 0.954 & -0.216 & & 0.880 & 0.427 \\
ERG10 & 0.943 & -0.154 & 0.833 & 0.468 \\
\% Var. explained & 87.7 & 7.4 & 56.4 & 38.7 \\
\hline
\end{tabular}

ring-width chronologies. However, when two RPCs are extracted by the Varimax rotation to achieve a simple structure of the loading distribution (Richman 1986), it produces two rotated PCs explaining $56.4 \%$ (RPC1) and $38.7 \%$ (RPC2) of the total variance, respectively. RPC1 has higher loadings, or correlation coefficients with the ring-width chronologies, for the lower elevations (ERG5-10), while RPC2 has higher loadings for the higher elevations (ERG1-4) (Table 3). Therefore, it can be assumed that RPC1 should represent signals of moisture conditions while RPC2 represents temperature signals. It is interesting to note that the highest loading of RPC1 is not found at the lowest elevation, but in the middle section (zone ERG5). When the scores of the two RPCs are used in correlation analysis to temperature and precipitation variables, RPC1 is significantly correlated to the precipitation variables, but not to the temperature variables, while RPC2 is correlated to both precipitation and temperature variables with statistical significance (Table 4a). In partial correlation analysis, we discover that RPC1's relationships to precipitation variables are essentially unchanged regardless the effects of winter temperature being removed or not (Table 4b). However, RPC2 representing the higher elevations is only related to temperature variables when the effects of precipitation are removed (Table $4 b$ ).

\section{Comparisons to other studies in the region}

Our results confirmed previous studies in this region that strong precipitation signals can be found in tree-ring data obtained from sites close to the upper treelines (Liang et al. 2006; Liu et al. 2006; Qin et al. 2013). For example, in Qin et al. (2013), correlations with previous July- 
Table 4 Pearson's correlations (a, $N=41)$ and partial correlations $(\mathrm{b}, d f=38)$ of the rotated principal component scores (RPCs) with current July-August (Tc78) and previous September-current March
(Tp9c3) temperatures, and current May-July (Pc567) and previous July-current June (Pp7c6) precipitation (1970-2010)

\begin{tabular}{|c|c|c|c|c|c|c|c|c|}
\hline \multicolumn{2}{|l|}{ (a) } & \multirow[t]{2}{*}{ RPC1 } & \multirow[t]{2}{*}{ RPC2 } & \multicolumn{3}{|l|}{ (b) } & \multirow[t]{2}{*}{ RPC1 } & \multirow[t]{2}{*}{ RPC2 } \\
\hline Climatic variables & Pearson's correlation & & & Climatic variables & Control variables & Partial correlation & & \\
\hline \multirow[t]{2}{*}{ Tc78 } & $r$ & -0.050 & 0.521 & Tc78 & Pp7c6 & $r$ & -0.223 & 0.542 \\
\hline & $p$ value & 0.758 & 0.000 & & & $p$ value & 0.167 & 0.000 \\
\hline \multirow[t]{2}{*}{$\mathrm{Tp} 9 \mathrm{c} 3$} & $r$ & 0.166 & 0.584 & Tp9c3 & Pp7c6 & $r$ & -0.035 & 0.495 \\
\hline & $p$ value & 0.298 & 0.000 & & & $p$ value & 0.828 & 0.001 \\
\hline \multirow[t]{2}{*}{ Pc567 } & $r$ & 0.493 & 0.360 & Pc567 & Tp9c3 & $r$ & 0.471 & 0.225 \\
\hline & $p$ value & 0.001 & 0.021 & & & $p$ value & 0.002 & 0.163 \\
\hline \multirow[t]{2}{*}{ Pp7c6 } & $r$ & 0.633 & 0.305 & Pp7c6 & Тр9c3 & $r$ & 0.620 & 0.165 \\
\hline & $p$ value & 0.000 & 0.052 & & & $p$ value & 0.000 & 0.310 \\
\hline
\end{tabular}

For partial correlations, Pp7c6 is used as the control variable for growth-temperature correlations and Tp9c3 is used for growth-precipitation correlations

current June precipitation were consistently higher than 0.6 at different elevations up to $4020 \mathrm{~m}$ at a site near Delingha, approximately $150 \mathrm{~km}$ northwest from our study site. However, our results also showed that there was a dramatic decrease in the strength of growth-precipitation relation at the upper treeline of $\sim 4200 \mathrm{~m}$, where the correlation with previous July-current June precipitation dropped to $0.45(p<0.01)$ (Table 2$)$. We also discovered that temperature signals can be found in the Qilian juniper ring-width data almost at all elevations (above $3820 \mathrm{~m}$ ), but with the strongest relationship at the upper treeline $(r=0.60, p<0.01$, for Tp9c3) (Table 2). This is in contrast to the findings by Qin et al. (2013) in Delingha, who found the correlations between ring-width series and Tp9c3 to be lower than 0.46, and the strongest growth-temperature relationship occurring below the highest sampling elevation.

In contrast to the findings by Gao et al. (2013) and Yang et al. (2013) in the Qilian Mountains, our RPCA results revealed two distinct modes of variation patterns: one represents mainly the upper elevations (RPC2 for zones ERG1-ERG4) and is temperature-sensitive, while the other one represents mainly the lower elevations (RPC1 for zones ERG5-ERG10) and is moisture-sensitive. Zhu et al. (2008) reported correlations of upper treeline tree ring data to winter temperature (previous September to current March) as high as 0.64 near Wulan, approximately $100 \mathrm{~km}$ north of our study site, which was comparable to our results. Some of these differences among various studies are probably caused by the difficulties associated with field identification of the upper climatic treelines: whether it is defined by climatic conditions or by topographic or soil conditions (Berdanier 2010; Körner 1998). In other words, when an apparent upper treeline is controlled mostly by thin soils and sleep slope gradients, then the growth of trees there may very well be limited by moisture conditions rather than by temperatures.

Local climatic conditions may also play a role as mean annual precipitation at Delingha is approximately 203 vs. $218 \mathrm{~mm}$ of Dulan during 1981-2010, while the differences in the actual moisture conditions at the sampling sites may be greater. Field observations indicate that the mountain slopes to the north and northeast of Delingha have poorer vegetation cover than those east of Dulan surrounding our sampling site, potentially due to differences in orographic rainfall. Zheng et al. (2009) examined growth-climate relationships at 6 sites within the wider area and found that tree ring data from the sites to the north (Delingha and Tianjun), which are drier, tended to have stronger and positive correlations with early growing-season precipitation and negative correlations with June temperature. In contrast, tree ring data from the eastern and southern sites (Wulan, Xiangride, and Dulan, respectively) tended to have stronger and positive relationships with winter temperatures. Additionally, in this study we sampled all trees regardless of ages. Therefore, sampling methods and the resulted age compositions of the samples used in chronology construction may lead to different sensitivity levels to climatic variables from the other studies (Fritts 1976).

We found that the first-difference data in growth-climate relationship analysis revealed new information that otherwise may not have been discovered. If we assume that the correlations between the original climatic data and tree growth are caused by variations in both high- and lowfrequency domains, then the correlations of the first-difference data represent the high-frequency component, which is similar to applying a high-pass filter to the data as in Gao et al. (2013). When growth-climate relationships display similar patterns in both the original and first- 
difference data, it means that the variation patterns in the tree ring series and climatic variable are dominated by variations in the high frequency domain, as in the case of growth-precipitation relations (Fig. $5 \mathrm{~g}, \mathrm{~h}$ ). When there are large differences in growth-climate relationships between the original data and first-difference data, it suggests that the relationships may be manifested differently in different frequency domains. For example, the positive correlations between tree ring data and current September temperature are most likely produced by the co-variations in the lowfrequency domain (Fig. 5a, c, e), since the correlations of the first-difference data are much weaker than those based on the original data. Similarly, the correlations between the radial growth and December temperature are mostly positive based on the original data, similar to correlations for other cold-season months (previous September-current March or April) (Fig. 5a, c, e). However, the first-difference data revealed statistically significant negative correlations between radial growth and December temperature at the high-frequency domain (Fig. 5b, d, f). These results can be explained by the common increasing trends in both tree ring (Fig. 4) and climatic data since the 1970s, while the variations patterns in the high frequency domain of tree ring series and December temperature are inversely correlated.

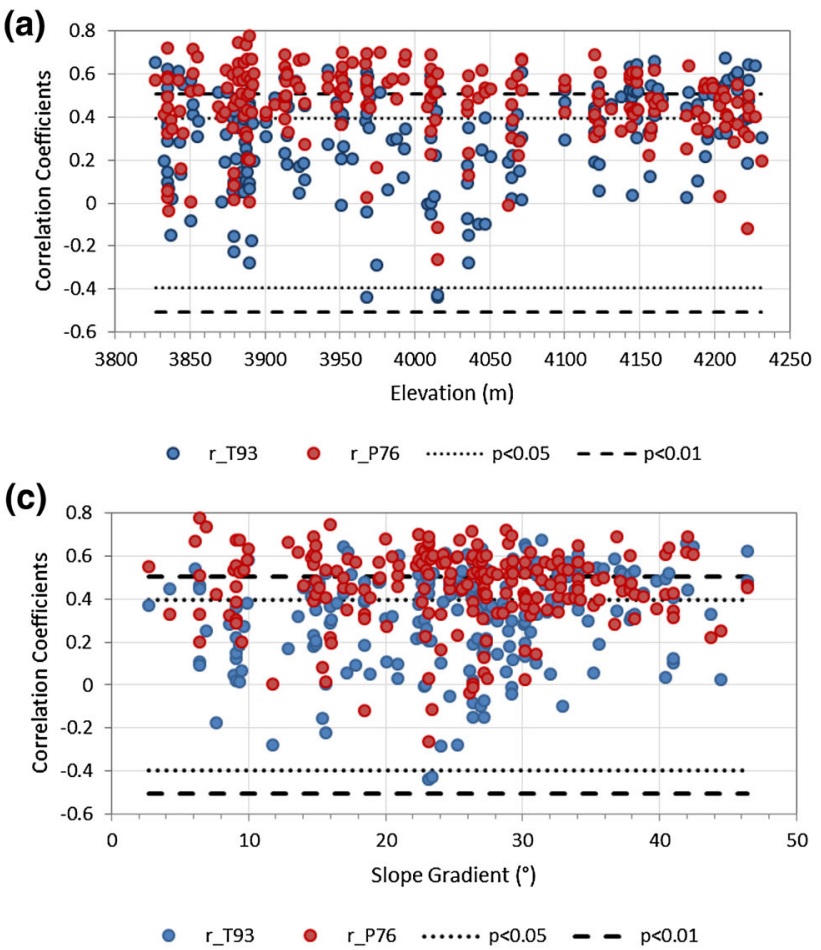

Fig. 7 Correlations of individual tree ring series to previous Julycurrent June precipitation (r_P76) and previous September-current March temperature (r_T93) plotted against elevation (a), growing season (April-August) direct solar radiation (b), and slope gradient

\section{Topographic influences on growth-climate relations for individual trees}

Figure 7 shows the Pearson's correlation coefficients of individual tree-ring series to previous September-current March temperature (r_T93) and previous July-current June precipitation (r_P76) during 1970-2010 plotted against elevation (Fig. 7a), growing season (April-August) direct solar radiation (Fig. 7b), and slope gradient (Fig. 7c). There seems to be a weak decreasing trend in growthprecipitation correlations with increasing elevation $(r=0.078, p=0.255)$ and an increasing trend in the growth-temperature correlations with increasing elevation $(r=0.244, p<0.01)$ (Fig. 7a). This confirms the earlier conclusion on the persistent relationships with precipitation at all elevations based on the ten ring-width chronologies. With increasing growing-season direct solar radiation, which is determined by local slope gradient $(r=0.500$, $p<0.01$ ) and aspect (southeast facing), the growth-temperature correlations show a decreasing trend $(r=-0.205$, $p<0.05$ ) (Fig. 7b), while the growth-precipitation relationship does not seem to be affected. For trees growing at locations receiving high solar radiation, temperature would tend to be a less limiting factor. The potential effect of solar radiation on enhancing moisture sensitivity does not

(b)

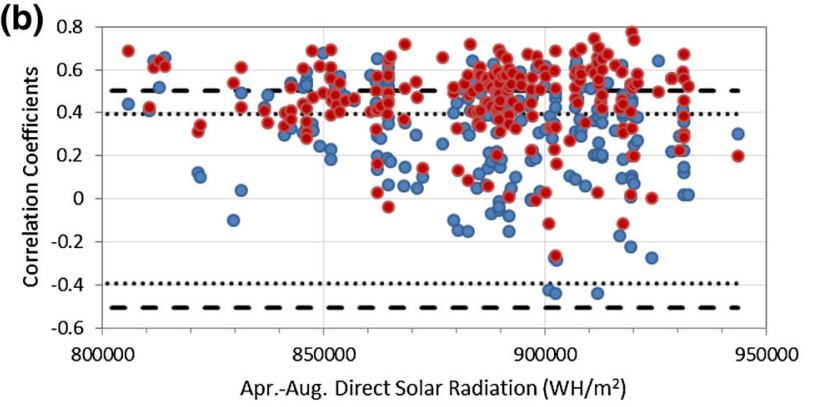

(d) - $r_{-}$T93 - r_P76 $\cdots \cdots \cdot$.... p $<0.05 \quad-p<0.01$

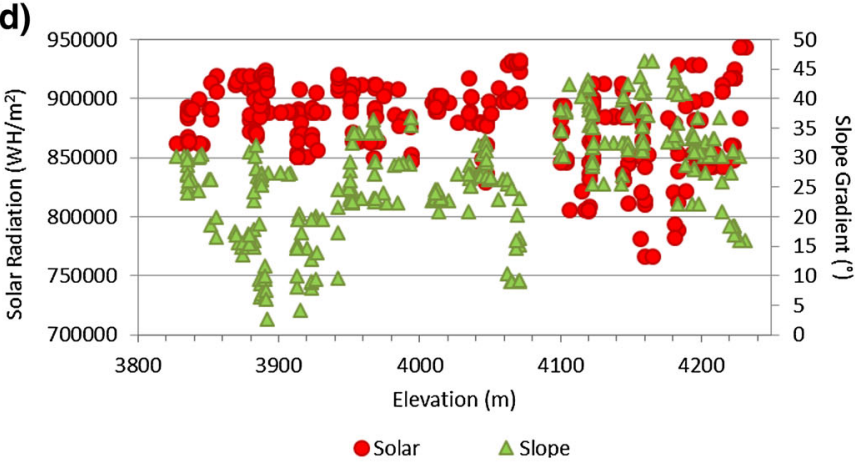

(c), and April-August direct solar radiation (solar) and slope gradient for individual trees plotted against elevation (d). Significance levels, represented by the dotted and dashed lines, are based on sample size of $N=25$ 
materialize, possibly because precipitation's effect on tree growth is already very dominating.

Generally speaking, with increasing slope gradient, there is poorer soil development and low capacity of water retention, and therefore, sensitivity of tree growth to moisture conditions should be enhanced. However, there is no obvious trend in growth-precipitation correlations with increasing slope gradient, while a weak increasing trend in growth-temperature correlations exists $(r=0.152$, $p<0.05$ ) (Fig. 7c). This may be due to the fact that the upper portion of the site has steeper slopes in general (correlation between slope and elevation $r=0.443$, $p<0.01$ ) (Fig. 7d), where temperature also acts as the major controlling factor of tree growth (Table 2; Fig. 6). Therefore, the potential effects of slope gradient on growth-precipitation sensitivity are obscured due to these complications. We also find that the upper portion of the sampling slope had large variability of growing season direct solar radiation, but with a general decreasing trend $(r=-0.316, \quad p<0.01) \quad$ with increasing elevation (Fig. 7d).

Although these topographic variables apparently have some influences on the growth-climate relationships at the level of individual trees, it seems that more factors of the microenvironments of individual trees need to be considered to achieve a better understanding regarding how growth-climate relationships may be influenced by topographic and soil conditions.

\section{Potential of using tree ring data for temperature reconstructions}

From our results, it is clear that Qilian juniper ring-width data have consistent relationships with precipitation variables except for the highest elevations sampled at our site. In other words, as long as we could avoid the upper treeline by approx. $30 \mathrm{~m}$, the ring width chronologies should be sufficiently good for reconstructions of past precipitation or moisture conditions, as successfully conducted in many previous studies (e.g., Zhang et al. 2003; Sheppard et al. 2004; Shao et al. 2005; Yin et al. 2008). For temperature reconstructions, if the goal is to achieve $50 \%$ or more explained variance in reconstruction calibration, then ideally the individual samples should potentially have correlations with temperature variables of $0.6-0.7$ or higher. Figure 8 shows histograms of growth-temperature relationships in different elevation zones. For correlations to summer temperature (July-August, r_T78), it seems to be

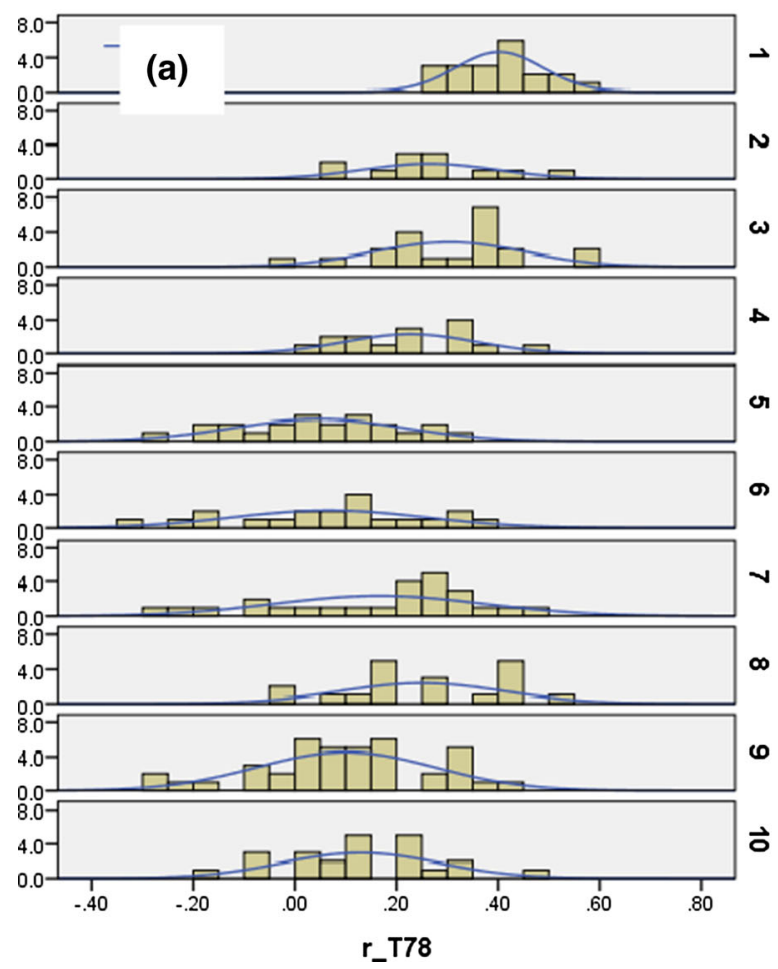

Fig. 8 Histograms of correlation coefficients between ring width series of individual trees and temperature variables at different elevation zones (ERG1-10): a correlations between ring width and

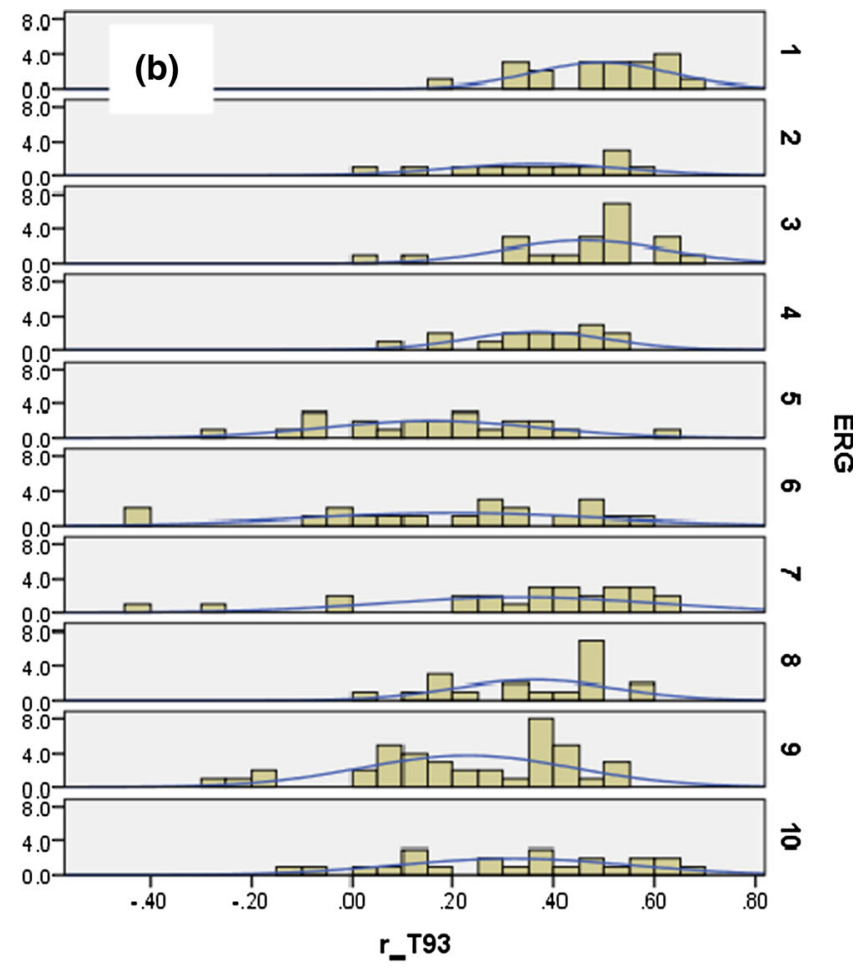

current July-August temperature (r_T78), and b correlations between ring width and previous September-current March temperature (r_T93) 
difficult to find trees with correlations higher than 0.6 (Fig. 8a), while for correlations to winter temperature (previous September-current March, r_T93), the probability of finding trees with high correlations to temperature increases in the higher elevation zones (Fig. 8b). However, the majority of the trees would still have relatively low correlations. Since these results were based on trees of all ages sampled indiscriminately at a given elevation, it might be possible to increase the potential of finding trees with high correlations to temperature by carefully selecting certain types of microenvironments of growth, such as those growing on gentle slopes with thick soils, while avoiding those with exposed roots or growing in rock fissures. This may also be achieved by post-sampling screening using mean sensitivity of the samples (Zhang et al. 2014) or other parameters representing the partitioning of variations in the low- and high-frequency domains.

\section{Conclusions}

In this study we sampled a total of 680 cores of Qilian juniper ( $S$. przewalskii Kom.) from 358 trees along an elevation gradient from approx. 3820 to $4230 \mathrm{~m}$ on a mountain slope east of the Qaidam Basin, northeastern Tibetan Plateau. Using 558 cores from 303 trees, we constructed ring-width chronologies representing ten different elevation zones. By analyzing the growth-climate relationships for these series we attempted to quantify the influences of elevation and other topographic variables as potential factors. We examined growth-climate relationships for all months during the year but with a focus on the summer (July-August) and winter (previous Septembercurrent March) temperatures and early growing season (May-July) and annual (previous July-current June) precipitation.

The ring-width chronologies of ten elevation zones did not show strong unidirectional trends in mean radial growth rates and other chronology statistics as elevation increases. Results from further analysis suggest that both temperature and precipitation are strong factors that influence radial tree growth at most elevations examined at this site, although the signals of precipitation are more robust than those of temperatures. This is mostly attributed to the semi-arid climate of the region in which moisture conditions are the predominant controlling factor of tree growth. However, we also discovered that at the upper treeline, the growth-precipitation relation weakened, which occurred in a rather narrow elevation range $(\sim 30 \mathrm{~m})$. We were able to distinguish two modes of variation patterns in the tree ring chronologies: the first mode mainly represented the variation patterns in the tree ring data from the elevation belt below $4100 \mathrm{~m}$. This variation mode corresponded to both summer and annual precipitation, but was not sensitive to winter temperature. In contrast, the second variation mode represented mainly the elevation belt above $4100 \mathrm{~m}$ and corresponded to both temperature and precipitation variables. In combination with the analysis of growth-climate relationship for individual trees, we can conclude that there is the potential of constructing good-quality temperaturesensitive ring-width chronologies in this area. However, caution must be exercised by locating the truly climatecontrolled upper treeline in the field and the best results might be achieved by sampling within $\sim 100 \mathrm{~m}$ along the upper treeline. We also attempted to explain the variation in growth-climate relationships using topographic factors other than elevation, including slope gradient and growingseason direct solar radiation extracted from digital elevation models. However, further studies are needed in order to achieve a better understanding on the variations in growth-climate relationships for individual trees in various microenvironments, using technologies such as dendrometers (Wang et al. 2015). Finally, it should be emphasized that the conclusions from our analysis should best apply to the upper treeline ecotone in semi-arid regions.

Author contribution statement ZY Yin and XM Shao: conception and design of the study, data collection, analysis and interpretation of data and paper writing. MQ Li: data collection and interpretation. Y Zhang: data collection and interpretation.

Acknowledgments The authors thank Dr. Hui Zhang, PhD. student Yang Wang and Feng Chen from the Institute of Geographic Sciences and Natural Resources Research, Chinese Academy of Sciences, for participation in collecting samples. This study was in part supported by grants from the CAS Strategic Priority Research Program (Grant No. XDA05080201), the China Natural Science Foundation (Grant No. 41471170), and University of San Diego (FRG\# 2014-2015 and 2015-2016). The authors thank China Meteorological Administration (CMA) for providing climatic data used in this study, US Geological Survey and NASA for providing the ASTER GDEM v2 data, and two anonymous reviewers for their constructive comments and suggestions that helped improve the manuscript substantially.

\section{Compliance with ethical standards}

Conflict of interest The authors declare that they have no conflict of interest.

\section{References}

Berdanier AB (2010) Global treeline position. Nat Educ Knowl 3:11 Briffa KR, Osborn TJ, Schweingruber FH (2004) Large-scale temperature inferences from tree rings: a review. Global Planet Change 40:11-26

Cook ER, Kairiukstis LA (1990) Methods of dendrochronology: applications in the environmental sciences. Kluwer, Dordrecht, pp 1-394

Cook ER, Seager R, Cane MA, Stahle DW (2007) North American drought: reconstructions, causes, and consequences. Earth Sci Rev 81:93-134 
Cook ER, Anchukaitis KJ, Buckley BM, D’Arrigo RD, Jacoby GC, Wright WE (2010) Asian monsoon failure and megadrought during the last millennium. Science 328:486-489

Esper J, Frank DC, Wilson RJS, Buntgen U, Treydte K (2007) Uniform growth trends among central Asian low- and highelevation juniper tree sites. Trees Struct Funct 21:141-150

Fritts HC (1976) Tree rings and climate. Academic Press, London

Gao LL, Gou XH, Deng Y, Liu WH, Yang MX, Zhao ZQ (2013) Climate-growth analysis of Qilian juniper across an altitudinal gradient in the central Qilian Mountains, northwest China. Trees Struct Funct 27:379-388

Graumlich LJ (1991) Sub-alpine tree growth, climate, and increasing $\mathrm{CO}_{2}$-an assessment of recent growth trends. Ecology 72:1-11

Graumlich LJ (1993) A 1000-year record of temperature and precipitation in the Sierra-Nevada. Quat Res 39:249-255

He MH, Yang B, Brauning A (2013) Tree growth-climate relationships of Juniperus tibetica along an altitudinal gradient on the southern Tibetan Plateau. Trees Struct Funct 27:429-439

Holmes RL (1983) Computer-assisted quality control in tree-ring dating and measurement. Tree Ring Bull 43:69-78

Körner C (1998) A re-assessment of high elevation treeline positions and their explanation. Oecologia 115:445-459

Körner C (2012) Alpine treelines-functional ecology of the global high elevation tree limits. Springer, Basel 220

Lang HR, Welch R (1999) Algorithm theoretical basis document for ASTER digital elevation models (ATBD-AST-08). Jet Propulsion Laboratory, Pasadena 63

Liang EY, Shao XM, Eckstein D, Huang L, Liu XH (2006) Topography- and species-dependent growth responses of Sabina przewalskii and Picea crassifolia to climate on the northeast Tibetan Plateau. Forest Ecol Manag 236:268-277

Liu LS, Shao XM, Liang EY (2006) Climate signals from tree ring chronologies of the upper and lower treelines in the Dulan region of the Northeastern Qinghai-Tibetan Plateau. J Integr Plant Biol 48:278-285

Liu Y, An Z, Linderholm HW, Chen D, Song H, Cai Q, Sun J, Tian H (2009) Annual temperatures during the last 2485 years in the mid-eastern Tibetan Plateau inferred from tree rings. Sci China Earth Sci 52:348-359

Mann ME, Zhang Z, Hughes MK, Bradley RS, Miller SK, Rutherford S, Ni F (2008) Proxy-based reconstructions of hemispheric and global surface temperature variations over the past two millennia. Proc Natl Acad Sci USA 105:13252-13257

Neukom R, Gergis J (2012) Southern hemisphere high-resolution palaeoclimate records of the last 2000 years. Holocene 22:501-524

Peng JF, Gou XH, Chen FH, Li JB, Liu PX, Zhang Y, Fang KY (2008) Difference in tree growth responses to climate at the upper treeline: Qilian Juniper in the Anyemaqen Mountains. J Integr Plant Biol 50:982-990

Qin C, Yang B, Melvin TM, Fan ZX, Zhao Y, Briffa KR (2013) Radial growth of Qilian Juniper on the northeast Tibetan Plateau and potential climate associations. PLoS One 8:15
Richman MB (1986) Rotation of principal components. J Climatol 6:293-335

Shao XM, Huang L, Liu HB, Liang EY, Fang XQ, Wang LL (2005) Reconstruction of precipitation variation from tree rings in recent 1000 years in Delingha, Qinghai. Sci China Earth Sci 48:939-949

Shao X, Xu Y, Yin ZY, Liang E, Zhu H, Wang S (2010) Climatic implications of a 3585-year tree-ring width chronology from the northeastern Qinghai-Tibetan Plateau. Quat Sci Rev 29:2111-2122

Sheppard PR (2010) Dendroclimatology: extracting climate from trees. Wires Clim Change 1:343-352

Sheppard PR, Tarasov PE, Graumlich LJ, Heussner KU, Wagner M, Österle H, Thompson LG (2004) Annual precipitation since 515 $\mathrm{BC}$ reconstructed from living and fossil juniper growth of northeastern Qinghai Province, China. Clim Dyn 23:869-881

Stokes MA, Smiley TL (1968) An introduction to tree-ring dating. University of Chicago Press, Chicago

Wang Z, Yang B, Deslauriers A, Bräuning A (2015) Intra-annual stem radial increment response of Qilian juniper to temperature and precipitation along an altitudinal gradient in northwestern China. Trees Struct Funct 29:25-34

White D, Richman M, Yarnal B (1991) Climate regionalization and rotation of principal components. Int J Climatol 11:1-25

Wing MG, Eklund A, Kellogg LD (2005) Consumer-grade global positioning system (GPS) accuracy and reliability. J Forest 103:169-173

Yang B, He MH, Melvin TM, Zhao Y, Briffa KR (2013) Climate control on tree growth at the upper and lower treelines: a case study in the Qilian Mountains, Tibetan Plateau. PLoS One 8. doi:10.1371/journal.pone.0069065

Yin ZY, Shao XM, Qin NS, Liang E (2008) Reconstruction of a 1436-year soil moisture and vegetation water use history based on tree-ring widths from Qilian junipers in northeastern Qaidam Basin, northwestern China. Int J Climatol 28:37-53

Zhang QB, Cheng GD, Yao TD, Kang XC, Huang JG (2003) A 2,326year tree-ring record of climate variability on the northeastern Qinghai-Tibetan Plateau. Geophy Res Lett 30

Zhang Y, Shao XM, Yin ZY, Wang Y (2014) Millennial minimum temperature variations in the Qilian Mountains, China: evidence from tree rings. Clim Past 10:1763-1778

Zheng YH, Zhu HF, Zhang YX, Shao XM (2009) Relationship between Sabina przewalskii radial growth and climatic factors at upper timber-lines in eastern mountainous region of Qaidam Basin. Chin J Appl Ecol 20:507-512

Zhu HF, Zheng YH, Shao XM, Liu XH, Xu Y, Liang EY (2008) Millennial temperature reconstruction based on tree-ring widths of Qilian juniper from Wulan, Qinghai Province, China. Chin Sci Bull 53:3914-3920 